\title{
Family Physicians Managing Medical Requests From Family and Friends
}

\author{
Esther Giroldi, $P b D^{1,2}$ \\ Robin Freeth, $M D^{1}$ \\ Maurice Hanssen, MD \\ Jean W.M. Muris, MD \\ Margareth Kay, $P b D, M D^{3}$ \\ Jochen W. L. Cals, PbD, MD \\ 'Department of Family Medicine, Maas- \\ tricht University, CAPHRI Care and Public \\ Health Research Institute, Maastricht, The \\ Netherlands \\ ${ }^{2}$ Department of Educational Develop- \\ ment and Research, Maastricht University, \\ School of Health Professions Education \\ (SHE), Maastricht, The Netherlands \\ ${ }^{3}$ Discipline of General Practice, The \\ University of Queensland, Herston, \\ Australia
}

Conflicts of interest: authors report none.

\section{CORRESPONDING AUTHOR}

Esther Giroldi, PhD

Department of Family Medicine

CAPHRI Care and Public Health Research Institute

Maastricht University

PO Box 616

Maastricht, The Netherlands

esther.giroldi@maastrichtuniversity.nl

\begin{abstract}
PURPOSE Although guidelines generally state that physicians should not treat their family members or friends (nonpatients), physicians regularly receive medical requests from nonpatients. We aimed to explore junior and senior family physicians' experiences with and attitudes toward managing medical requests from nonpatients.
\end{abstract}

METHODS We conducted a qualitative study with 7 focus groups with junior and senior physicians. We performed a thematic analysis during an iterative cycle of data collection and analysis.

RESULTS When confronted with a medical request from a nonpatient, physicians first oriented themselves to the situation: who is this person, what is he or she asking of me, and where are we? Physicians next considered the following interrelated factors: (1) nature/strength of the relationship with the nonpatient, (2) amount of trust in his/her own knowledge and skills, (3) expected consequences of making mistakes, (4) importance of work-life balance, and (5) risk of disturbing the physician-patient process. Senior physicians applied more nuanced considerations when deciding whether to respond, whereas junior physicians experienced more difficulties dealing with these requests, were less inclined to respond, and were more concerned about disturbing the existing relationship that a person had with his/her own physician.

CONCLUSIONS This study provides insight into the complexity that physicians face when managing medical questions and requests from nonpatients. Facilitated group discussions during which experiences are shared can help junior physicians become more confident in dealing with these complex issues as they formulate their own personal strategy regarding provision of medical advice or treatment to family and friends.

Ann Fam Med 2018;16:45-51. https://doi.org/10.1370/afm.2152.

\section{INTRODUCTION}

$\mathrm{P}$ roviding medical advice and treatment to family members and friends is common practice for physicians, even though it is discouraged in current medical guidelines. ${ }^{1}$ More than $99 \%$ of physicians receive requests from family members asking for medical advice, diagnosis, or treatment, ${ }^{2}$ and $85 \%$ of physicians have written at least 1 prescription for a nonpatient. ${ }^{2,3}$ Reasons for providing care to family members include convenience, cost savings, and the perception of having greater knowledge or concern than colleagues. Yet physicians may also decide not to intervene in the care of relatives or friends, concerned by a lack of objectivity, fearing misdiagnosis, or recognizing an inability to provide complete and continuous care. ${ }^{2,4-7}$ In addition, most codes of ethics, such as the Good Medical Practice code of the General Medical Counsel, ${ }^{1}$ state that physicians should not treat family members. Opinions emanating from these codes specify that physicians may treat relatives and friends in case of minor ailments or in an emergency situation, when no other health care professional is available. ${ }^{8}$ The literature also suggests that treating family members can lead to increased diagnostic testing and costs..$^{9}$ Despite their reservations, physi- 
cians may still feel compelled to be involved in the care of a family member or friend. When confronted with illness in the family, physicians face conflicting personal and professional expectations of themselves and others (eg, family members, other physicians). ${ }^{10}$

Although requests from family and friends are common and the literature reveals some of the complexity involved in managing them, there is little empirical evidence on how physicians themselves experience these requests. Understanding these experiences can be informative for guiding current and future physicians in how to respond. The purpose of this study was therefore to explore the experiences and attitudes of physicians when they encounter medical requests from family and friends (nonpatients). We explored this phenomenon in a family medicine setting given that family physicians may be more likely to receive a variety of medical requests because of their general medical expertise. We were primarily interested in the experiences of junior physicians, who are still in an early stage of their career, and those of senior physicians, who are more experienced in the field.

\section{METHODS}

\section{Study Design}

We performed a qualitative study using focus groups ${ }^{11}$ and inductive thematic analysis ${ }^{12}$ to establish a knowledge base for understanding the experiences and attitudes of physicians regarding medical requests from family members and friends. We chose to use focus groups to obtain a better and deeper understanding of these experiences by facilitating discussion among participants. The focus group discussions were thematically analyzed with an iterative process of data collection and analysis, allowing for adjustments in the focus of subsequent focus groups. ${ }^{13}$ The study was exempt from review by the Medical Ethics Committee of Maastricht University Medical Centre.

\section{Setting and Participants}

This study was conducted within the family medicine specialty training (FMST) program of Maastricht University. We recruited junior physicians (ie, residents) in the first year of this program. Being relatively inexperienced as earlycareer practicing physicians, residents may actively struggle with managing requests from nonpatients. We nonetheless expected residents to have plenty of experiences to share in the focus groups, given their 6 years of medical school, working experience in hospital settings as physicians before entering into program, and first months in the program. To explore whether experiences differed for senior physicians, we also asked supervisors (ie, family physicians with a minimum of 5 years of working experience in family medicine who supervised a resident in their own practice) to participate. In total, 44 junior physicians and 51 senior physicians from existing educational groups within the FMST of Maastricht University were asked to participate. Apart from logistic reasons, the extra benefit of recruiting participants in existing groups was that confidentiality and trust were already present. Participants periodically discussed professional and personal issues in these groups as part of the FMST. We deemed this discussion important because participants would be more open to honestly sharing their experiences and thoughts on this matter. The focus groups were held in the faculty buildings of the FMST. All participants were informed of the study both verbally and in writing, and all signed informed consent.

We completed 5 focus groups with junior physicians and 2 focus groups with senior physicians. Ultimately, 33 junior physicians and 16 senior physicians participated. Size of each focus group and characteristics of its participants are shown in Table 1 .

\section{Data Collection}

An experienced and independent moderator (behavioral scientist and FMST instructor) conducted all focus groups in Dutch using an interview guide (Figure 1). Two 6th-year medical students (R.F. and M.H.) were present to observe and take notes about the ambiance during and the nature of the discussions. All focus group discussions were audio-recorded and videorecorded, and transcribed verbatim by these students.
Table 1. Characteristics of Focus Group Participants

\begin{tabular}{|c|c|c|c|c|c|}
\hline $\begin{array}{l}\text { Focus Group } \\
\text { (Physicians) }\end{array}$ & $\begin{array}{c}\text { Physicians, } \\
\text { No. }\end{array}$ & $\begin{array}{c}\text { Male, } \\
\%\end{array}$ & $\begin{array}{l}\text { Age, Mean } \\
\text { (Range), y }\end{array}$ & $\begin{array}{l}\text { Experience } \\
\text { as FP, Mean } \\
\text { (Range), y }\end{array}$ & $\begin{array}{c}\text { Experience } \\
\text { Before FMST } \\
\text { Program, } \\
\text { Mean } \\
\text { (Range), y }\end{array}$ \\
\hline 1 (junior) & 5 & $2(40.0)$ & $28.8(25-33)$ & - & $4.0(2-6)$ \\
\hline 2 (junior) & 8 & $1(12.5)$ & $27.3(26-30)$ & - & $3.0(2-7)$ \\
\hline 3 (junior) & 8 & $3(37.5)$ & $28.0(25-33)$ & - & $2.5(1-4)$ \\
\hline 4 (junior) & 5 & $3(60.0)$ & $26.4(25-29)$ & - & $2.2(1-4)$ \\
\hline 5 (junior) & 7 & $2(28.6)$ & $28.1(25-31)$ & - & $3.0(1-6)$ \\
\hline 6 (senior) & 8 & $6(75.0)$ & $51.6(48-57)$ & $19.3(14-31)$ & - \\
\hline 7 (senior) & 8 & $4(50.0)$ & $49.3(40-63)$ & $17.0(9-25)$ & - \\
\hline
\end{tabular}




\section{Data Analysis}

We performed an inductive thematic analysis to identify themes within the data. ${ }^{12}$ Two authors (R.F. and M.H.) independently coded every transcript and a third (E.G.) coded 2 transcripts. Inconsistencies in coding were resolved by discussion. Four authors (R.F., M.H., E.G., and J.W.L.C.) held regular meetings to organize the codes into themes and to develop schemes to visualize the themes and the relationships between them. During the analysis of new transcripts, themes were continuously reviewed and refined. The 2 final versions of the schemes were reviewed and refined by all the members of our multidisciplinary research team with backgrounds in family medicine (J.W.L.C., J.W.M.M., M.K.), health sciences (E.G.), medical education (E.G., M.K., J.W.M.M.), medical communication (E.G.), and physicians' health (M.K.). The analysis of the fifth focus group discussion did not yield any new and relevant themes. We conducted 2 more focus group (1 with junior physicians, 1 with senior physicians) to assess whether data saturation was reached, which was indeed the case. As a member check, an overview of the findings (Figure 2) was sent to the participants, which did not lead to any revisions in our analysis.

\section{RESULTS}

\section{Factors That Physicians Consider}

A range of factors emerged as important considerations for physicians when they receive a medical request from a nonpatient and determine how they respond.
These factors are presented in Figure 2. The first and central factor is orientation to the situation. After considering this factor, physicians consider 5 additional factors. All factors are illustrated with quotations in Table 2 and discussed in detail below.

\section{Orientation to the Situation}

The central factor, orientation to the situation, consisted of a set of key questions that physicians considered when determining whether to respond to the nonpatient's medical request: who is this person, what is he or she asking from me, and where are we located at this particular moment?

Of these 3 questions, the nature of the request itself ("what") seemed to be the most important for physicians, because it determined the urgency of the situation. In the case of an emergency, all other factors became irrelevant as an immediate professional response was required (exemplified by quote 1). The "what" question also remained key in nonurgent problems, because physicians would consider the severity of the condition and may have been more reluctant to treat a person with a serious illness.

The setting in which the request was made ("where") also influenced the physician's decision about how to respond. Some settings were considered more practical and confidential for diagnostic purposes than others (quote 2). For instance, parties or family gatherings were less private venues.

Finally, the physician's relationship with the nonpatient ("who") was an initial issue to consider. Physicians were more likely to respond to a request made by a person they felt close to (quote 3).

1. Introduction of the topic: "Every doctor receives medical requests from people in their social environment. Although this is a common phenomenon, it receives little attention in the literature. With this study we would like to obtain insight in the attitudes and experiences of physicians when receiving medical requests from family and friends, ie, nonpatients. We define nonpatients as a person not officially listed with the physician, but with a significant personal (family or friend) relation with that physician. With this group discussion, we aim to understand how you experience requests from nonpatients, whether you experience any difficulties, and what factors you consider when dealing with such requests."

2. Initiation of the discussion: "'Imagine the following situation. You are at a birthday party of a family member. During a conversation with your brother in-law, he asks you the following question: 'Last week I was looking in the mirror and I saw a strange-looking rash. Could you take a look at it, and can you maybe prescribe me something?'"

3. Opening question: "Who of you has ever experienced such a situation? Who of you gets medical requests from nonpatients? Can you share this experience?"

4. Probing questions: The moderator continuously facilitates in-depth discussions between participants by inviting participants to elaborate and to respond to each other, and by asking the following questions.

- "What factors did you consider when receiving such a request?/What made you (not) respond?"

- "Who of you has ever given medical advice to or treated a nonpatient?"

- "What advantages/disadvantages/difficulties did you experience?"

- "Where is the limit for you and why?"

- "Do you feel treating nonpatients has any influence on the quality of care, compared to treating a regular patient?"

5. Closing question: "Do you need more guidance/education/training about this topic?"

\section{Nature and Strength of the Relationship}

Throughout the focus groups, there was robust discussion about the importance of the relationship between the physician and the nonpatient. The emotional relationship to the nonpatient, irrespective of whether the person was a family member or friend, had a large influence on the decision to provide advice or treatment. Physicians described a feeling of personal responsibility and a willingness to invest in the ones they loved. They wanted to be informed about how their loved ones were doing medically, which also enabled 


\section{Table 2. Factors Considered and Quotations}

\begin{tabular}{|c|c|}
\hline Factor & Quotation \\
\hline \multicolumn{2}{|l|}{ Orientation to the situation } \\
\hline What is being requested? & $\begin{array}{l}\text { 1. "If it's at a party, then the answer's 'no.' At that moment, I'm not a physician, just a guest at the party. } \\
\text { Unless, of course, that it's something very serious, a life-or-death situation that I have to deal with. Otherwise, } \\
\text { they need to go to their own physician or call me at another time. And then if it's something really serious, I } \\
\text { still advise them to go to their own physician." [JP20, FG3] }\end{array}$ \\
\hline Where are we? & $\begin{array}{l}\text { 2. "If I were talking one-on-one to someone face-to-face, at somebody's house, and he asks me something, then } \\
\text { I am much more inclined to listen, to have a look, or to listen further than I would if I were, for example, at a } \\
\text { party. I don't think that's the time or place. I am busy doing something else. And neither do you have the peace } \\
\text { and quiet to listen properly, so I am always much more circumspect in that sort of environment." [JP25, FG4] }\end{array}$ \\
\hline $\begin{array}{l}\text { Who is making the } \\
\text { request? }\end{array}$ & $\begin{array}{l}\text { 3. "So it has a lot to do with how much compassion I have with somebody whether I will say, 'I'll just draw that } \\
\text { from my magician's hat for I know the answer!'" [SP15, FG7] }\end{array}$ \\
\hline \multirow[t]{3}{*}{$\begin{array}{l}\text { Nature and strength of } \\
\text { the relationship with the } \\
\text { nonpatient }\end{array}$} & $\begin{array}{l}\text { 4. "If it were the neighbor's wife, then I think it would be different. I think I would have said, 'Your physician } \\
\text { has examined you, so now wait for the results.' But because it's your own mother, you are therefore more wor- } \\
\text { ried, you go one step further. You travel that extra mile for your own family." [JP22, FG4] }\end{array}$ \\
\hline & $\begin{array}{l}\text { 6. "You have the knowledge. And if I say to an IT expert, 'Hey, have a look at this will you? My computer won't } \\
\text { work,' you expect to get a simple answer. So I therefore thought that I should also be a bit more relaxed in my } \\
\text { attitude. I have been more so over the past few years. With family too." [SP12, FG7] }\end{array}$ \\
\hline & $\begin{array}{l}\text { 7. "Just say, you hear something from your father and you don't say anything about it. Your father will then } \\
\text { assume, 'Oh, she heard it and has said nothing, so then it's probably alright.' So it's a matter of my responsi- } \\
\text { bility towards my family, but your family does expect you to do something if there's a problem." [JP27, FG5] }\end{array}$ \\
\hline \multirow[t]{4}{*}{$\begin{array}{l}\text { Amount of trust in one's } \\
\text { own knowledge and skills }\end{array}$} & $\begin{array}{l}\text { 8. "As long as I have no doubts. If I have doubts, then I would certainly just say go to see your own physician." } \\
\text { [JP16, FG3] }\end{array}$ \\
\hline & $\begin{array}{l}\text { 9. "I am conscious of this, because if I know that you probably are less careful in your examination, and that } \\
\text { you probably don't think it's pleasant to contemplate that there could be something seriously amiss with a } \\
\text { member of your family. And that you therefore would prefer not to go looking for something. So I am very } \\
\text { aware ... and thus alert to the situation. And I am convinced that if I am alert to what's going on, it will turn } \\
\text { out alright." [SP4, FG6] }\end{array}$ \\
\hline & $\begin{array}{l}\text { 10. "Coincidentally, that happened to me recently. Someone had shaved her legs with a razor and sent me } 3 \\
\text { photos asking me what she should do. And then I answered, very clearly, 'I haven't seen the full picture. I } \\
\text { don't know the whole story.' This is the sort of situation that I keep myself well away from." [JP2, FG3] }\end{array}$ \\
\hline & $\begin{array}{l}\text { 11. "Sometimes, I have a blind spot as far as members of my family are concerned. Things that I just don't see } \\
\text { or perceive as being less serious than they really are." [SP11, FG7] }\end{array}$ \\
\hline \multirow[t]{2}{*}{$\begin{array}{l}\text { Expected consequences of } \\
\text { making mistakes }\end{array}$} & $\begin{array}{l}\text { 12. "Things can sometimes just go wrong in the medical profession, but I would be scared of being blamed for } \\
\text { this. I wouldn't like to be blamed, let's say, by a family member or a good friend. They are my close friends, } \\
\text { and I enjoy a good relationship with them. And I want to keep it like that." [JP23, FG4] }\end{array}$ \\
\hline & $\begin{array}{l}\text { 13. "You don't want to have it on your conscience if, for example, you have taken a step backwards and there- } \\
\text { fore no action has been taken, and something serious is missed. With anyone, I mean a normal patient let } \\
\text { alone a member of your own family. Then there's also a level of personal involvement." [JP30, FG5] }\end{array}$ \\
\hline \multirow[t]{2}{*}{$\begin{array}{l}\text { Importance of work-life } \\
\text { balance }\end{array}$} & $\begin{array}{l}\text { 14. "Really, I would prefer it if, when I am finished with work, then I am really finished. I am then not very inter- } \\
\text { ested in examining people and so forth. I see being a physician more as a profession, not as my identity as a } \\
\text { person. That's what I hope to stay feeling and what I really want to be the case." [JP11, FG2] }\end{array}$ \\
\hline & $\begin{array}{l}\text { 15. "I have certainly learned over time how to split the } 2 \text { roles in my head. As a family physician just starting } \\
\text { out, you gave well-intentioned advice or you listened to the complaints of family members, then you recognize } \\
\text { that the roles of family member and physician are interwoven in the words that you choose or the interven- } \\
\text { tions that you carried out. Eventually, you become more aware of just what cap you are wearing at any given } \\
\text { time." [SP2, FG6] }\end{array}$ \\
\hline $\begin{array}{l}\text { Risk of disturbing the physi- } \\
\text { cian-patient process }\end{array}$ & $\begin{array}{l}\text { 16. "It is also good that the patient's own family physician is able to keep tabs on things... So if I go ahead and } \\
\text { sort out problems for people and they have, for example, the same trouble every month, the physician will be } \\
\text { unaware that this is a recurrent problem each month ... and loses the overview." [JP25, FG4] }\end{array}$ \\
\hline
\end{tabular}

them to reassure themselves (quote 4). This feeling of personal responsibility sometimes caused physicians to give advice or treatment to nonpatients without being asked to do so; for example, if they recognized a medical condition that the nonpatient was unaware of, or saw that a nonpatient's existing medical condition was deteriorating. Physicians explained that then they felt it was their duty to inform the nonpatient of this serious medical condition (quote 5). Some physicians viewed the answering of a medical request as "service to a friend" (quote 6). In answering a request or not, physicians also considered the expectations of their family members and friends (quote 7). For instance, a father may expect his son to help him with his medical problem, whereas in other relationships, such as boyfriendgirlfriend relationships, this expectation is less evident. Furthermore, physicians mentioned that their professional curiosity triggered them to respond to requests. 
Amount of Trust in One's Knowledge and Skills Physicians mentioned that being more confident in their own medical expertise made them more likely to assist a nonpatient. Some junior physicians indicated that their familiarity with the problem at hand largely determined whether they would respond to the request (quote 8 ). Physicians' personal insecurities could augment these concerns, reducing their confidence in their ability to manage the presenting issue. Senior physicians described feeling more confident when providing medical advice to nonpatients than when they were younger. As they gained experience over the years, they became more confident in their skills and more aware of the potential pitfalls of treating nonpatients (quote 9). Physicians' trust in their ability to respond to a request also depended on availability of information. For instance, if a physician was approached by a friend via a text message, he/she was not able to gather all the information required (quote 10). Both junior physicians and senior physicians expressed concerns about the risk of losing objectivity when caring for loved ones.
They felt there was an increased chance of making a mistake, and they expressed concerns that they might either falsely reassure or falsely generate worry in their family member or friend (quote 11).

\section{Expected Consequences of Making Mistakes}

Junior physicians expressed their anxiety about making mistakes when advising or treating nonpatients. Although this concern was also present when treating their own patients, the consequences of that mistake would be different. They were afraid that mistakes would negatively affect close relationships with people (quote 12). In addition to the risk of jeopardizing the relationship, junior physicians were worried that they could cause physical harm to their loved ones, and this concern could prevent them from responding to requests. Physicians also recognized, however, the risk of failing to take action when it was needed (quote 13). Those who had made a mistake in the past when treating a nonpatient felt less inclined to respond to a new request.

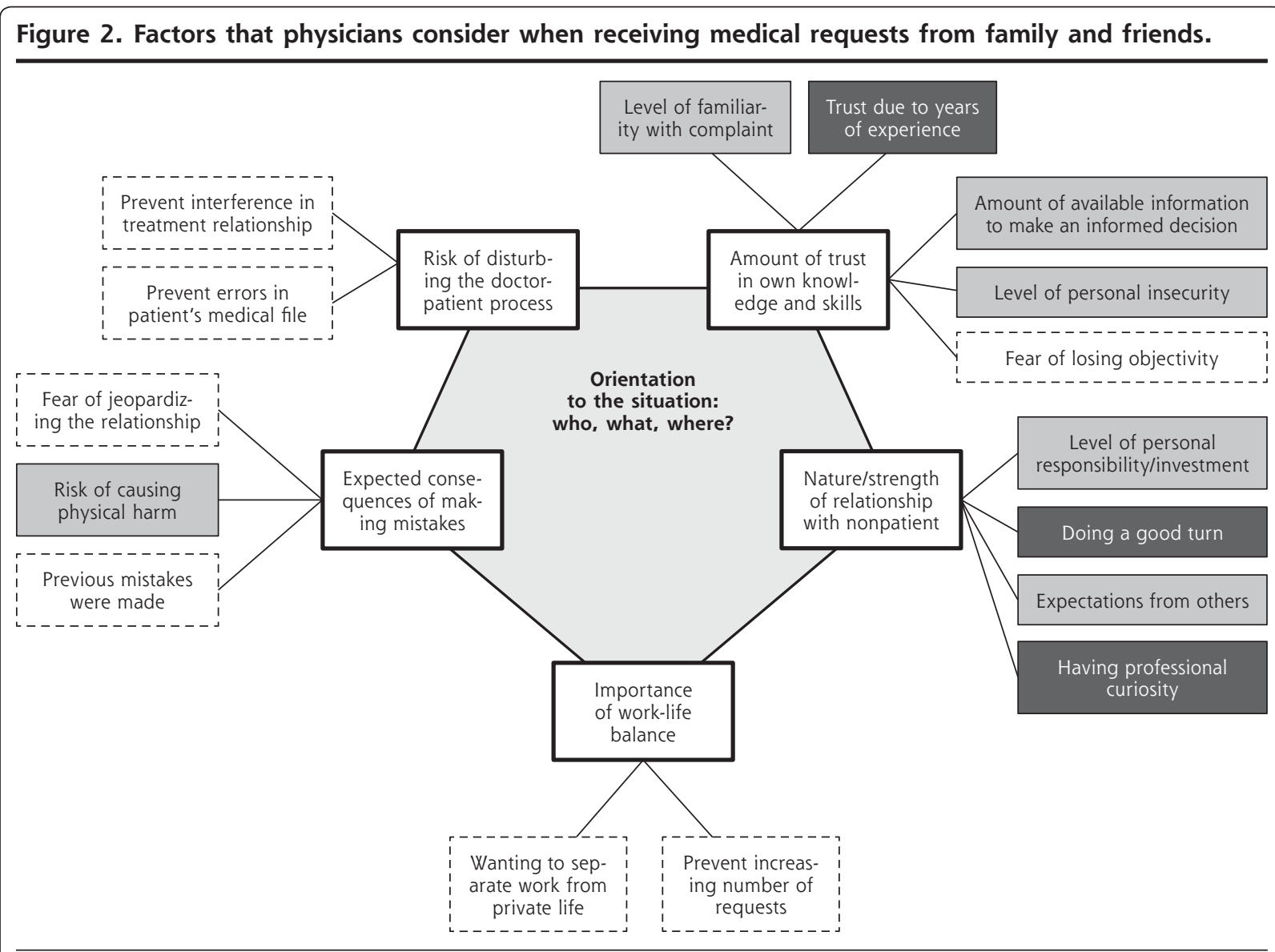

The first factor physicians consider is orientation to the situation (pentagon). They frame the potential consultation by asking the questions who, what, and where? Thereafter, physicians consider 5 interrelated factors (boxes outlined in bold). For each of these factors, specific considerations could lead to different outcomes: decision to agree to the request (dark gray boxes), decision to decline the request (boxes with dashed outline), or decision could go either way (light gray boxes). 


\section{Importance of Work-Life Balance}

Although some physicians said they considered themselves to be physicians 24 hours a day, they did not want to be constantly engaged with patient care as they valued their private life. They were happy to respond to an urgent request for medical care. In less urgent situations, they preferred to avoid such requests and enjoy their free time (quote 14). Physicians were very aware that responding to a request once could inadvertently lead to more requests in the future. Although junior physicians often struggled to separate their work from their private life, senior physicians said that through the years, they had learned to handle this issue more effectively (quote 15).

\section{Risk of Disturbing the Physician-Patient Process}

Another reason for not responding to requests of nonpatients was not wanting to interfere in the treatment relationship that the nonpatient had with his or her own physician. Treating nonpatients could also result in an incomplete medical record, although this concern was raised only by the junior physicians (quote 16).

\section{DISCUSSION}

All physicians in our study had experiences with requests for medical care from nonpatients. Our findings provide a framework for understanding how physicians engage with these requests, recognizing the central need for physicians to orient themselves to the situation (who, what, where) and articulating the 5 important subsequent considerations: what is the nature of the relationship with the person, how much do you trust your own expertise, are you afraid of making mistakes considering the consequences, how do you separate work and private lives, and how do you view the potential impact of advising or treating nonpatients on the physician-patient process? Senior physicians were more confident with handling medical questions from family or friends; through positive and negative experiences, they had learned to manage these dilemmas over time. Junior physicians found this process more difficult, and they were more cautious about avoiding the potential consequences and pitfalls.

There are very few publications on the phenomenon of physicians receiving medical requests from family and friends. Most of these are opinion pieces that primarily discuss which criteria to apply when treating these nonpatients. ${ }^{9,14}$ Several surveys have documented the high occurrence of the phenomenon. 2,5,15 Our study confirms how common it is, as all participants shared multiple personal experiences related to managing requests from nonpatients.
The main reasons offered by international guidelines for being cautious when responding to requests relate to concerns that objectivity may be compromised, taking a history or performing a medical examination targeting sensitive areas could be inadequate, and physicians could be inclined to treat problems beyond their expertise. ${ }^{8}$ Although our participants also recognized these concerns, they regularly weighed them against other issues. The decision of whether to respond to a request is a complex one. The few qualitative studies focused on this topic confirm this complexity. A Malaysian study in a primary care setting identified similar issues involved with treating family members, such as feelings of social responsibility and fear of losing objectivity. ${ }^{16}$ Chen et a ${ }^{10}$ interviewed 8 general practitioners about their involvement in the care of severely ill family members; they reported that being a physician-family member was challenging, complicated by the need to manage these 2 conflicting roles. Expectations from relatives and friends and even from colleagues can complicate these dilemmas. In a case study, Fromme and colleagues ${ }^{17}$ analyzed their personal experiences with being involved in the care of a loved one. Their description of a dynamic tension between personal and professional roles when a physician-family member gets involved in the family member's care was central to this study. They recommend that physicians ask themselves, "Could I engage in this situation without a medical degree?" When the answer is no, physicians should be more attuned to the risks related to being medically involved in a loved one's care. Krall ${ }^{18}$ explored these issues and reinforced the advice of La Puma et $\mathrm{al}_{1}{ }^{2}$ who offered 7 questions that physicians should ask themselves before engaging in a consultation with family or friends.

Discussion about these issues should be contextualized through an understanding of the usual pathways to care. It is likely that physicians do not give medical advice to their families more than nonphysicians do. Family members play a vital role in the help-seeking pathway and regularly provide health and medical advice. According to the Lay Referral Pathway to health care, informal care is routinely sought within the family to sanction the decision to seek formal health care. ${ }^{19}$ Often, advice from a community expert is also sought. If the family member or friend happens to be a physician, then seeking advice from that person in an informal setting would be a part of the normative pathway to care. When considering this broader context of the sociology of health access, it becomes clear that any simplistic application of the current guidelines to not give advice or treatment to relatives is not feasible. This is a complex space, and physicians require training and experience to negotiate these issues safely. 
Our study has several strengths. This is the first focus group study that explores experiences and attitudes of junior and senior family physicians with regard to medical requests from family members and friends. The use of focus groups has provided an in-depth exploration of the complexity involved in decision making when it comes to helping these nonpatients with their medical concerns. Having an independent group moderator not involved in the participants' training or assessment limited the influence of the researchers' perspectives on the data collection process. We have enhanced the trustworthiness of our findings by performing independent coding and member checks.

Our study also had some limitations. One risk with focus groups is that participants are inclined to give socially acceptable answers. We mitigated this risk by engaging participants who had a trusting relationship (promoting frank answers) and by having an independent professional moderate the groups. With regard to generalizability, data collection took place at only a single family medicine training center and among physicians already familiar with each other and comfortable with sharing personal experiences. Moreover, we have solely explored experiences in the family medicine setting, which may make our findings less applicable to other medical settings.

This study provides a framework to improve the understanding of the complex processes involved when physicians decide how to respond to family and friends requesting medical advice and care. A more comprehensive understanding requires exploration of the experiences of the nonpatients themselves, who are likely to present different narratives. For example, children of physicians could shed an interesting light on this phenomenon.

Sharing their experiences was informative for the participants, increasing their awareness of the various risks when advising or treating family and friends, and highlighting the personal and complex considerations required when making these decisions. Implementing facilitated group discussions around ethical issues such as these would likely provide powerful teaching opportunities for junior physicians. It may help increase their confidence in dealing with these issues as they formulate their own personal strategies regarding advising and treating family and friends. Lastly, the observed complexity involved when dealing with requests from family and friends may justify a careful reconsideration of the current guidelines on this matter.

To read or post commentaries in response to this article, see it online at http://www.AnnFamMed.org/content/16/1/45.

Key words: family medicine; qualitative research, medical education; primary care; practice-based research
Submitted January 15, 2017; submitted, revised, June 19, 2017; accepted July 11, 2017.

Acknowledgments: The authors would like to thank the junior and senior physicians who participated in this study and Jos Sleijpen for moderating the focus group discussions. We thank Carol Herman for assistance in quote translation.

\section{References}

1. General Medical Council. Good Medical Practice 2013 Web site. http://www.gmc-uk.org/guidance/good_medical_practice.asp. Accessed Sep 15, 2016.

2. La Puma J, Stocking CB, La Voie D, Darling CA. When physicians treat members of their own families. Practices in a community hospital. N Engl J Med. 1991;325(18):1290-1294.

3. Aboff BM, Collier VU, Farber NJ, Ehrenthal DB. Residents' prescription writing for nonpatients. JAMA. 2002;288(3):381-385.

4. Boiko PE, Schuman SH, Rust PF. Physicians treating their own spouses: relationship of physicians to their own family's health care. J Fam Pract. 1984;18(6):891-896.

5. Dusdieker LB, Murph JR, Murph WE, Dungy Cl. Physicians treating their own children. Am J Dis Child. 1993;147(2):146-149.

6. Reagan B, Reagan P, Sinclair A. 'Common sense and a thick hide'. Physicians providing care to their own family members. Arch Fam Med. 1994;3(7):599-604.

7. Scarff JR, Lippmann S. When physicians intervene in their relatives' health care. HEC Forum. 2012;24(2):127-137.

8. American Medical Association. The AMA Code of Medical Ethics' Opinion on Physicians Treating Family Members: Opinion 8.19 Self-treatment or Treatment of Immediate Family Members. http:// journalofethics.ama-assn.org/2012/05/coet1-1205.html. Published May 2012. Accessed Sep 15, 2016.

9. Schneck SA. "Doctoring" doctors and their families. JAMA. 1998; 280(23):2039-2042.

10. Chen FM, Feudtner C, Rhodes LA, Green LA. Role conflicts of physicians and their family members: rules but no rulebook. West J Med. 2001;175(4):236-239, discussion 240.

11. Stalmeijer RE, Mcnaughton N, Van Mook WN. Using focus groups in medical education research: AMEE Guide No. 91. Med Teach. 2014;36(11):923-939.

12. Braun V, Clarke V. Using thematic analysis in psychology. Qual Res Psychol. 2006;3(2):77-101.

13. Frambach JM, van der Vleuten CP, Durning SJ. AM last page. Quality criteria in qualitative and quantitative research. Acad Med. 2013; 88(4):552.

14. Kamerow D. Doctors treating their families. BMJ. 2014;348:g4281.

15. Evans RW, Lipton RB, Ritz KA. A survey of neurologists on selftreatment and treatment of their families. Headache. 2007:47(1): 58-64.

16. Nik-Sherina $\mathrm{H}, \mathrm{Ng}$ C-J. Doctors treating family members: A qualitative study among primary care practitioners in a teaching hospital in Malaysia. Asia Pac Fam Med. 2006;5(2).

17. Fromme EK, Farber NJ, Babbott SF, Pickett ME, Beasley BW. What do you do when your loved one is ill? The line between physician and family member. Ann Intern Med. 2008;149(11):825-831.

18. Krall EJ. Doctors who doctor self, family, and colleagues. WMJ. 2008;107(6):279-284.

19. Chrisman NJ. The health seeking process: an approach to the natural history of illness. Cult Med Psychiatry. 1977;1(4):351-377. 